\title{
Manager's Task to Support Integrated Autonomy at the Workplace: Results from An Intervention
}

\author{
Tomas Backström ${ }^{1}$, Marie Moström Åberg ${ }^{2}$, Bengt Köping Olsson ${ }^{1}$, Lena Wilhelmson ${ }^{3}$ \& Mattias Åteg ${ }^{2}$ \\ ${ }^{1}$ School for Innovation, Design and Technology, Mälardalen University, Sweden \\ ${ }^{2}$ School of Technology and Business Studies, University of Dalarna, Sweden \\ ${ }^{3}$ Department of Education, Stockholm University, Sweden \\ Correspondence: Tomas Backström, School for Innovation, Design and Technology, Mälardalen University, P.O. \\ Box 325, SE-63105 Eskilstuna, Sweden. Tel: 46-16-153-230. E-mail: tomas.backstrom@mdh.se
}

Received: May 22, 2013

doi:10.5539/ijbm.v8n22p20
Accepted: October 12, $2013 \quad$ Online Published: October 15, 2013

URL: http://dx.doi.org/10.5539/ijbm.v8n22p20

\begin{abstract}
A new managerial task arises in today's working life: to provide conditions for and influence interaction between actors and thus to enable the emergence of organizing structure in tune with a changing environment. We call this the enabling managerial task. The goal of this paper is to study whether training first line managers in the enabling managerial task could lead to changes in the work for the subordinates. This paper presents results from questionnaires answered by the subordinates of the managers before and after the training.

The training was organized as a learning network and consisted of eight workshops carried out over a period of one year (September 2009-June 2010), where the managers met with each other and the researchers once a month. Each workshop consisted of three parts, during three and a half hours. The first hour was devoted to joint reflection on a task that had been undertaken since the last workshop; some results were presented from the employee pre-assessments, followed by relevant theory and illuminating practices, finally the managers created new tasks for themselves to undertake during the following month.

The subordinates' answers show positive change in all of the seventeen scales used to assess it. The improvements are significant in scales measuring the relationship between the manager and the employees, as well as in those measuring interaction between employees. It is concluded that the result was a success for all managers that had the possibility of using the training in their management work.
\end{abstract}

Keywords: integration, autonomy, manager, enabling, communication, dialogue, improvisation

\section{Introduction}

This paper focuses on new competencies needed by managers in today's working life. A post-industrial work system has emerged in companies as an answer to an increased need for innovation and flexibility to meet global competition and customer commands, as well as the expectations from a skilled workforce who seek satisfaction at work. In a post-industrial work system the coordination between departments and people within the organization, and between the organization and its environment are not pre-defined by the organizational structures in the same way as they were in the industrial work system (Backström, Wilhelmson, Olsson, Åteg, \& Åberg, 2011). Given these conditions the need for a new managerial task arises: to provide conditions for and influence interaction between actors to enable the emergence of coordination in tune with a changing environment. We call this the enabling managerial task. We base our thinking on theories about management and human interaction.

The goal of this paper is to study if training first line managers in the enabling managerial task may lead to changes in the work for the subordinates. This paper presents results from questionnaires answered by the subordinates of the managers before and after the training. The questionnaires deal with integrated autonomy (the relationship between manager and subordinates in the enabling task), interaction between subordinates (the central mechanism used in the enabling task), and attractiveness of the work place (a comprehensive measure of workers' overall impression of their work). Other results from the project will be presented in subsequent articles. 


\section{Management Theories and Integrated Autonomy}

Managers had two different kinds of tasks in the traditional industrial work system. The work system itself was designed to ensure stability, quality and efficiency and the first task was to ensure that it worked as planned; to focus on the task of the organization and to administer the work system The second task was to drive development, often organized as activities outside the work system for production; in projects and special meetings or departments for development and innovation, and in training of the personnel. Most theories for work organization and management include this duality, see for example (Yukl, 2002). The administrative task can be connected to a leadership behavior characterized by control and transactions and the development task by a focus on the relationship between the leader and the employees, see for example (Bass, 1999; Fleichman \& Harris, 1962).

The enabling managerial task is a third one for managers. It arrived with the post industrial work system and the need to provide conditions for and influence interaction between employees. This is a task that has been studied by a few researchers for example (Surie \& Hazy, 2006). We were inspired by the role of the director of an improvisational theater group in our study, and then called it the directing managerial task. The first mention of the directing managerial task is made in Swedish by (Backström, Döös, \& Wilhelmson, 2006). In this article we translate it to the enabling managerial task.

The enabling managerial task is not now about controlling subordinates since the post-industrial work system is too complicated to be planned, managed, and controlled by one person (Streatfield, 2001). And it is not about the relation between the leaders and the subordinates. It is instead about providing preconditions for employee decisions and responsibility. Two tasks are in focus; to balance integration and autonomy, and to foster interaction and communication. These tasks will be described.

\subsection{Balancing Integration and Autonomy}

In studying the relation between the leader and the employee in a control perspective it is possible to construct a scale consisting of the following stages: Autocratic, Consultative, Participative, Consensus, and Laissez-Fair (Flamholtz, 1986). We can analyze them by using two dimensions: autonomy - integration and thinking - acting. All leadership styles, except Laissez-Fair, are meant to ensure integration of the actions of the employees towards the goal of the organization. In all leadership styles, except the Autocratic, there is a belief that using employees' experience and thinking may be of benefit for the organization, implying a need of autonomy in the thinking of the employees. Only in the Consensus style of leadership are the employees are given some control of decision making. Thus there is a need for integration of the employees' thinking towards the goal of the organization, so that they are able and willing to participate in decisions favourable to the whole organization. But none of the traditional relationships between the leader and the employee includes autonomy of the actions of the latter.

The enabling manager strives towards a leadership style where all four possibilities are fulfilled, both autonomy and integration in both thinking and acting of employees. Autonomy in action is demanded of employees since adaptation and innovation towards increased fitness is meant to start when the employee independently adjust his/her way of working in a new situation, for example in the meeting with a customer who has new kinds of demands. We call this leadership style Integrated autonomy.

Autonomy means that the employee is able, knows how to, and wants to be autonomous. It requires a distribution of decisions to the employee paired with enough competence and other resources in his/her hands. Individual competence may be assumed to concern cognitive and existential dimensions influencing individual autonomy, and communicative and collective dimensions influencing social integration (Hagström, Backström, \& Göransson, 2009). Autonomy provides opportunity for change. However, if it is not balanced by integration, it can lead to fragmentation and chaos. Integration involves the employees consciously or unconsciously lending themselves to the organizing structures like culture (Backström, Hagström, \& Göransson, 2013; Shweder \& Sullivan, 1993), institutions (Berger \& Luckmann, 1966; Edquist \& Johnson, 1997) and relatonics (Backström \& Döös, 2008) that emerge in interactions and replace those which disappeared with the post-industrial system. Integration provides the opportunity of coordination and building on past experiences. However, if integration is not balanced it may lead to group thinking (Janis, 1972), collective oppression (Barker, 1999) and hence stagnation. However, if there are balanced and high levels of both autonomy and integration, and a desire for increased fitness, a complex system emerges that can learn and develop, and can adapt to external changes and may even shape the future (Backström, 2009).

It may seem a paradox to have both autonomy and integration at the same time, and thus something that should be avoided. However paradoxes can be seen as something that give energy to the system, and that the problem with them disappears when you transform them to a higher system level (Lewis, 2000; Sánchez-Runde \& Pettigrew, 
2003). From a complex system theory perspective paradoxes like this and others; top-down-bottom-up, stability-flexibility, and control-learning, are what separates a living system from a dead one. The ability to keep separate differences are also associated with creative achievement (Kurtzberg \& Amabile, 2001). Suggested ways of managing such paradoxes are to have open discussions, experimentation, common goals and a focus on the task, which may lead to a view of diversity as something good.

Integrated autonomy is not only a leadership style and a specific kind of relationship between the manager and the subordinates. The subordinates also rise through the ranks to become co-workers with a decision making power of their own. And their behavior and relations among themselves are part of the leadership. The interaction between subordinates is of central importance for managers using the enabling task perspective.

\section{Human Interaction Theories}

Three different branches of theories about human interaction have been used in this project: Balanced communication, Dialogue, and Improvisational approach. Each of them was a theme of the training, thus three of six themes in the training dealt with human interaction.

\subsection{Balanced Communication}

Our main theoretical base for understanding the concept balanced communication is the Meta Learning model (Losada, 1999). It consists of six dimensions; inquiry-advocacy, other-self and positive-negative. The roots of the dimensions can be found in Interaction Process Analysis (IPA) (Bales, 1950). Positive-negative was extensively used by Bales, but Losada was also influenced by Gottman (Losada, 1999). Inquiry and Advocacy (I and A) were influenced by (Argyris \& Schön, 1978) who emphasized that the balance between inquiry and advocacy could lead to more effective action. The strategic planning process has contributed with the concepts other-self $(\mathrm{O}$ and $\mathrm{S})$, since high performance teams were expected to balance environmental scan and internal scrutiny.

A key feature in the Meta Learning model is the concept of emotional space, which refers to the effect of positivity in creating expansive emotional spaces that open possibilities for action, while negativity created restrictive emotional spaces. High performance teams showed appreciation and encouragement to other members in the team, created emotional spaces that were expansive, and opened possibilities for action and creativity. In contrast, low performance teams had very restricted emotional spaces, a lack of mutual support and enthusiasm, and showed distrust and cynicism. High performance teams had a ratio of about 5.6, i.e. it was five to six times more common to have a positive utterance than a negative one. Medium performance teams had a ratio of about 1.9, and low performance teams about 0.4 (Losada \& Heaphy, 2004).

\subsection{Dialogue}

Our main theoretical base for understanding the concept of dialogue in small group communication is the Dialogue Competence Model (DCM). The DCM maintains that interaction quality is dependent on the dialogue competence of the participants, as they co-construct their communicative context (Wilhelmson, 1998, 2002, 2006). This competence includes the ability to speak assertively from one's own perspective and yet listen closely to aspects of the reality as revealed by others. Two important qualities include the ability for critical self-reflection (to look upon one's truth as if it were one's preconception), and the ability to critically reflect on statements made by others. This indicates that there are four kinds of dialogue competence necessary for participants to engage in quality dialogue. They are labelled as speaking and listening competencies and critical self-reflection and critical reflection competencies (ibid). They are characterised by the following abilities:

- Closeness to the individual perspective, by which we mean an ability to contribute to knowledge formation by speaking in one's own voice and by asserting reflected experiences relevant for the topic under discussion.

- Closeness to the perspectives of others, by which we mean an ability to listen carefully and with curiosity to the narratives of others while seriously trying to understand what is meant.

- Distance from the individual perspective, by which we mean the ability to think of one's own truths as eventually being prejudiced, as well as to critically reflect on self-perceptions.

- Distance from the perspectives of others, by which we mean an ability to critically reflect, with integrity, on assertions made by others from one's own experience and knowledge.

These abilities produce an integrating, as well as a differentiating quality in the communication. An integrative dialogue competence makes the participant able to connect his or her way of thinking to those of others in an open-minded way. A differential dialogue competence makes the participant able to distinguish among perspectives and to analyze and penetrate problems in more depth (ibid). 
Dialogue competence is difficult to practice since participants are easily trapped in communicative habits of power relationships and gender conversational styles. Power relationships: whether communication is symmetric or asymmetric in character is decisive for the learning quality. Symmetric communication contributes to a positive 'developmental learning', for most participants. Asymmetric communication can lead to 'illusory learning' for those who dominate, and 'negative learning' for those who are dominated. Gender conversational styles: whether communication is characterized by competitiveness or co-operation also influence the possibilities for participants to learn. Moreover, these different ways of talking seem to be gender related (Coates, 1996, 1997). Women's group conversation is mostly either symmetrically or asymmetrically co-operative, while men's group conversation is mostly symmetrically or asymmetrically competitive (Wilhelmson, 1998).

A leader who supports dialogue in work groups need strategies to handle communicative habits of power and gender as well as to support abilities to talk, listen, critically reflect and critically self-reflect. The task is to support and hold back, to balance among perspectives, and to foster dialogue competence among the members of the organization. The enabling leader can support competent dialogue behavior through role modeling. The members in a team learn how to cooperate by guiding each other in group conversations which become true dialogues. The aim is to learn from each other's experience and to act in tune with each other and thus create a synergy effect, this being a positive learning environment for each other. Participants support each other in a learning process where they deliberately influence each others' way of thinking and acting.

\subsection{Improvisational Approach}

Integrated autonomy demands an ability of the group of co-workers to handle that they have differing and autonomous views on the one hand, with the need to integrate these differences to common regimented thinking and action on the other. We believe that ways to interact in improvising groups may provide a model for this. It seems that the co-activity thus released results in a general intensification of the group members, a condition based on the individuals' mental processes that have been described in terms of flow (Csikszentmihalyi, 1990). When an individual is involved in activities where she has to make use of the lion part of her competences and skills, i.e. the task is relevant to her competence, resulting in intense efforts to complete the task, we have the basic condition for reaching the flow level.

The fact that creativity research has often compared individual-based processes and group-based processes in a way that the same concepts have been used to describe similar but not identical phenomena, may have contributed to some misunderstandings regarding different kinds of creativity. Notwithstanding this, a condition similar to flow can also be reached in groups through intensive interaction. When group members' various initiatives are linked and build upon each other, while everyone is focused on what grows out of the collective work, and in which team members' individual basic common skills are appropriate for the task, then we have one basic condition to achieve a state of interaction which we call Groove. The concept of groove emphasizes two central aspects. Firstly, it stresses the significance of the characteristic and quality in the way each group member relates to initiatives of other's. The second aspect is a function of the first, it propounds that the quality of member's way of interacting should be understood in correspondence with the group idea, the result of the social thinking process (Olsson, 2008).

Thus, in the same way as the term 'Enabling leadership' is inspired by artistic activity, the description of the momentary, intense and constructive group interaction is also inspired by the arts. Again, in comparisons between studies of individual creativity and team creativity, the amount of initiative, i.e. idea proposals, becomes a measurement of creativity. To sum up, it is about being consciously present in what is happening and focusing on what emerges through interaction, what we here term the group idea (Olsson, 2007). When all initiatives from the interacting group members are related and timed to an emerging, common vehicle of thinking, we call this vehicle the group idea. The group idea as a constructive collectively generated creation based on the group members' attention and focus on what occurs in and through interaction (Sawyer, 2001). We argue that an improvisational approach to the structures that emerge through group social interaction stimulates group creativity.

With an improvisational approach the focus of the group member is more on the spontaneous responses of the co-activity, rather than pushing their own opinion. They maintain confidence in the group's ability to manage these responses constructively, rather than just their own. One group member's comment or response is the starting point for the others' responses. If the listeners however are already clear about what they want to say and think about how they should express themselves while someone else is speaking, then there is no dialogue (Isaacs, 1999). Such a focus on the individual's own perception runs counter to seeing the emerging group idea as a guide.

The focus is moved away from the individual level to the group level using the concepts of circular response and group idea. The group idea is not produced by a process of addition of responses, one after the other, it is produced 
in and through all group members' common interaction (Follett, 1918). Follet demonstrates emphatically that the interaction is more important for group performance than the individual team member's skills and characteristics. Her understanding of the foundations of social processes is based on the concept of circular responses. Behavior and responses are not a function of the environment, but a function of structures that emerge in the interaction between the individual and the social environment. This is a type of circular causality (Haken, 1996), which is not really a circular process because it never comes back to the same point, but rather moves in a spiral.

\section{Research Questions for this Article}

The project that formed the basis for this paper is an implementation of the manager's enabling task. It started with identifying skills that managers need to have to perform the managers enabling task. The competencies identified are primarily the ability to organize for autonomy and integration, where the ability to create good conditions for interaction and communication are important elements. Through workshops with first-line managers we have tried to train and develop these skills among them. In order to develop our understanding of the enabling task, this paper deals with the following two research questions with two sub-questions:

1) Is it possible to change behavior of the subordinates by training their managers?

2) What changes will training of managers in the enabling task introduce?

(i) Has the training changed the interactions between employees at the workplace?

(ii) Is there more of integrated autonomy at the workplace?

\section{Research Design and Method}

Eighteen managers took part in the research project where they received training in the enabling managerial task: twelve women and six men, nine of them within the public sector (government authority, health care, municipal activity) and nine of them within the private sector (motor industry, bank, manufacturing industry, real estate service and a health service company). The workplaces were chosen to represent large and small enterprises, as well as private and public ones. Originally twenty managers took part in the research project, but two of them dropped out half way into the project. The managers' and their subordinates' experiences of some aspects in their work were assessed before and after the training.

\subsection{The Training}

The training was organized as a learning network and consisted of eight workshops held over a period of one year (September 2009-June 2010), where the managers met with each other and the researchers once a month. The workshops had different themes. The focus of the first was to arrive at a good social climate and working habits in the group and to communicate resume of the project as a whole. The following six workshops dealt with themes presumed to be central for the enabling managerial task: Dialogue competence, Balanced communication, Integrated autonomy, Attractive work, Group creativity through improvisation and External relations. In the eighth and last workshop the group summed up the project and formulated the enabling managerial task on experiences drawn from it.

Each workshop took three and a half hours and consisted of three parts. The first hour was devoted for joint reflection on a task that had been undertaken since the last workshop; then some results were presented from the employee pre-assessments, followed by relevant theory and illuminating practices. Finally the managers created new tasks for themselves to undertake during the following month.

\subsection{Pre-and Post-Assessments}

Three questionnaires were given to all employees in the managers' workgroups before and after the training (spring 09 and autumn 10). One focused on interaction between subordinates, the other dealt with integrated autonomy while the third survey examined the respondents' perceptions of the workplace.

The Interaction-questionnaire consisted of 35 questions concerning the interaction in the meetings at the work place. Answers were given on a five graded scale from "Very seldom or never" to "Very often or always". It was answered by 266 respondents in the pre-assessment and 215 in post-assessment.

The Integrated autonomy questionnaire consisted of 33 statements. Reactions were given on a five-point scale from "Not at all" to "Completely". It was answered by 261 respondents in the pre-assessment and 215 in post-assessment.

To assess changes in the employees' experience of work we used an established and comprehensive questionnaire designed to measure how attractive a workplace is. It consists of 179 questions and has been used in several years in many workplaces. This tool examines not only the factors respondents considered to be important for the work 
to be experienced as attractive, but also how the current work fulfills this. Reactions were given on a five-point scale from "Not at all" to "Completely". The questionnaire was answered by 223 respondents in the pre-assessment and of 167 respondents in post-assessment.

\subsection{Data Analyses}

Factor analyses (Principal Axis Factoring with rotation) were used on each questionnaire to reduce data to the most important factors. For each factor we constructed a scale by taking the mean value of the questions most important for the factor.

Four scales from the Interaction-questionnaire:

- Democracy. (Cronbach's Alpha $\alpha=0.79$ )

Questions included in the scale: You have become closer to each other through mutual understanding? How often are all present people involved in the conversation? How often is the experience of all the people present of equal importance? You have understood each others' views better? You have created a positive social climate?

- Interest. $(\alpha=0.64)$

Questions: How often are questions asked when someone does not understand? How often do you allow each other to have his/her say? How often do you show that you have changed your opinion (discarding one's own interpretation in favor of someone else's and then talked about it)? How often are you trying to really understand each other? How often are opinions challenged and discussions started (scrutinized to understand better or give a deviant opinion)?

- Individual activity. $(\alpha=0.69)$

Questions: How often do you, personally, question what is said and start a discussion (scrutinize or give a deviant opinion)? How often do you take your allocation of the available time for talking? How often do you ask when you do not understand? (With a negative direction) How often do you refrain from talking, even though you have something to say? How often do you refrain from questioning what is said, even though you have a deviant opinion?

- Gender equality. $(\alpha=0.69)$

Questions: How often is the talk of men and women valued equal? How often do men and women share talking time equally?

Four scales from the integrated autonomy questionnaire.

- Individual autonomy. $(\alpha=0.65)$

Statements included in the scale: I contribute to the development of new ways to work, or design my new work tasks and routines. I often use the existing possibilities to develop my work. I often independently take contact with people that can be of use for me in my work.

- Group autonomy. $(\alpha=0.79)$

Statements: My colleagues and I, rather than my manager, decides which work tasks to carry out. My colleagues and I, rather than my manager, decides how to perform the work. My colleagues and I, rather than my manager, decide the frames and conditions for work.

- Integration into groups. $(\alpha=0.56)$

Statements: My colleagues and I think in a similar way. My colleagues and I have similar values, when it comes to work. My colleagues and I have similar work tasks.

- Integration into organization. $(\alpha=0.77)$

Statements: In my workgroup we spend a lot of time to finally reach a point where everyone understands the goals of their work. I discuss the goals of my work with my colleagues or manager. I get feed-back on my work in relationship to the goals.

Nine scales from the comprehensive questionnaire measuring employees' general experience of the work.

- Creativity: $(\alpha=0.65)$

Statements included in the scale: I have a thinking, creating work. I am allowed to solve problems in work. I participate in the development of the business.

- Satisfaction: $(\alpha=0.71)$ 
Statements: I believe I do important things at work. My work is demanding in a good way. I am doing a good job.

- Physical milieu: $(\alpha=0.78)$

Statements: The work facilities are clean. The air is good. The facilities and equipments are good.

- Relationship to management: $(\alpha=0.93)$

Statements: I trust my immediate manager. The communication with my immediate manager works well. My immediate manager shows trust in me.

- Appreciation: $(\alpha=0.73)$

Statements: I receive extra appreciation for my work through rewards that increase when I perform well. I receive extra appreciation for my work through rewards chosen specifically for me. My work makes others think I have a high status.

- Physical work: $(\alpha=0.73)$

Statements: I work with my hands and use my practical skills. I move between different places at my work place.

I have a practical creating work.

- Social milieu: $(\alpha=0.88)$

Statements: We are honest with each other. We are open to each other. We help and support each other.

- Social contacts: $(\alpha=0.56)$

Statements: I socialize with fellow workers at work. I socialize with fellow workers at leisure time. I meet with other people at work, besides of my fellow workers.

- Travel to and from work: $(\alpha=0.75)$

Statements: My work place is in an appealing environment. I find it easy to get from the work to other things I want to do. I find it easy to get to the work

The impact of the training was analyzed by comparing means from pre-assessment and post-assessment. The T-test was used to get an indication of the strength of change. The questionnaires were given to all group members, thus even small changes in mean values are significant.

The pre- and post-assessments also included collection of qualitative data which is not used in this article. Some of them are instead reported in (Wilhelmson, Åberg, Backström, Olsson, \& Åteg, Forthcoming).

\section{Results}

Looking at all respondents (see table 1) we see that communication between employees has developed positively during the period between the pre-and post-assessment for all the four scales used to measure interaction between subordinates. The level of Democracy has increased most, but also active individual shown high gains.

Table 1. Pre-and post-assessments of communication habits, a comparison between means for all employees in the included workgroups

\begin{tabular}{ccccc}
\hline Scales & & $\mathbf{N}$ & Mean & t-value \\
\hline \multirow{2}{*}{ Democracy } & pre-ass & 264 & 3.31 & $2.63^{* *}$ \\
& post-ass & 208 & 3.46 & \\
Interest & pre-ass & 261 & 3.67 & 0.44 \\
& post-ass & 210 & 3.69 & \\
Active individual & pre-ass & 258 & 3.26 & \multirow{2}{*}{1.78} \\
\multirow{2}{*}{ Gender equality } & post-ass & 211 & 3.35 & \\
& pre-ass & 239 & 3.78 & 0.85 \\
& post-ass & 203 & 3.85 & \\
\hline
\end{tabular}

**. Correlation is significant at the 0.01 level (2-tailed). 
Both autonomy and integration of the employees has increased, when we look at the answers from all respondents (see table 2). Integration has increased most, both into the group and into the organization. The individual autonomy has increased more than the autonomy of the group.

Table 2. Pre-and post-assessments of autonomy and integration, a comparison between means for all employees in the included workgroups

\begin{tabular}{ccccc}
\hline Scales & & $\mathbf{N}$ & Mean & t-value \\
\hline Individual autonomy & pre-ass & 259 & 3.57 & 0.73 \\
& post-ass & 209 & 3.62 & \\
Group autonomy & pre-ass & 258 & 3.07 & 0.38 \\
& post-ass & 208 & 3.11 & \\
Integration into group & pre-ass & 259 & 3.35 & 1.75 \\
& post-ass & 214 & 3.47 & \\
Integration into organiz & pre-ass & 257 & 3.59 & $2.02 *$ \\
& post-ass & 214 & 3.74 & \\
\hline
\end{tabular}

*. Correlation is significant at the 0.05 level (2-tailed).

All nine scales have increased between pre- and post-assessment for the questionnaire assessing how attractive the work place is (see table 3). The scales Physical milieu and Relation to management have the most positive development. Appreciation and Social milieu also have high increases. Appreciation had a very low level in the pre-assessment.

Table 3. Pre- and post-assessments of employees' perception of the work, a comparison between means for all employees in the included workgroups

\begin{tabular}{lllll}
\hline Scales & & N & Mean & t-value \\
\hline Creativity & pre-ass & 241 & 3.62 & 1.13 \\
Satisfaction & post-ass & 178 & 3.71 & \\
& pre-ass & 241 & 4.17 & 0.21 \\
Physical milieu & post-ass & 180 & 4.19 & \\
& pre-ass & 241 & 3.31 & $4.01^{* *}$ \\
Relation to management & post-ass & 179 & 3.66 & \\
& pre-ass & 241 & 3.94 & $3.33^{* *}$ \\
Appreciation & post-ass & 179 & 4.27 & \\
& pre-ass & 241 & 1.99 & $2.18^{*}$ \\
Physical work & post-ass & 180 & 2.19 & \\
& pre-ass & 241 & 3.18 & 0.19 \\
Social milieu & post-ass & 178 & 3.20 & \\
& pre-ass & 241 & 3.78 & $2.17^{*}$ \\
Social contacts & post-ass & 179 & 3.96 & \\
& pre-ass & 241 & 4.15 & 0.36 \\
Travel to and from work & post-ass & 180 & 4.18 & \\
& pre-ass & 241 & 3.67 & 0.94 \\
\hline is significant at the 0.01 level $(2-$ tailed $) * *$ Correlation is significant at the 0.05 level (2-tailed).
\end{tabular}

**. Correlation is significant at the 0.01 level (2-tailed); *. Correlation is significant at the 0.05 level (2-tailed).

\section{Discussion}

The enabling task is to provide conditions for and influence interaction between employees in order to encourage autonomy and integration into emerging organizational structures.

\subsection{Is It Possible to Change Behavior of the Subordinates by Training Their Managers?}

Three questionnaires were given to all employees in the managers' workgroups before and after the training. One focused on interaction between subordinates, the second dealt with integrated autonomy while the third survey 
examined respondents' perceptions of the workplace. Seventeen scales were used to measure the effect of the training in the enabling task for managers, according to statistical analyzes of the answers to these questionnaires.

The subordinates' answers show a positive change on all of the seventeen scales. We thus conclude that it is possible to change the subordinates' behavior by training their managers.

\subsection{What Changes will Training of Managers in the Enabling Task Introduce?}

For six of the scales there is a significant increase, they are ordered by amount of increase:

1) Physical milieu. Statements included in the scale: The work facilities are clean. The air is good. The facilities and equipments are good.

2) Relationship to management. Statements included in the scale: I trust my immediate manager. The communication with my immediate manager works well. My immediate manager shows trust in me.

3) Democracy. Questions included in the scale: You have become closer to each other through mutual understanding? How often are all present people involved in the conversation? How often is the experience of all the people present of equal importance? You have understood each others' views better? You have created a positive social climate?

4) Appreciation. Statements included in the scale: I receive extra appreciation for my work through rewards that increase when I perform well. I receive extra appreciation for my work through rewards chosen specifically for me. My work makes others think I have a high status.

5) Social milieu. Statements included in the scale: We are honest with each other. We are open to each other. We help and support each other.

6) Integration into organization. Statements included in the scale: In my workgroup we spend a lot of time to finally reach a point where everyone understands the goals of their work. I discuss the goals of my work with my colleagues or manager. I get feed-back on my work in relationship to the goals.

It is a bit surprising that Physical milieu is the factor that has the highest increase. Our interpretation of this is that when managers have better communication with their subordinates, physical milieu is something they can change rather rapidly, and the results are very obvious and easy to measure. Also Relationship to management and Appreciation indicate a better relationship between the manager and subordinates. There is more trust and communication between them, and managers are able to see the subordinates and appreciate their efforts. This is important for one part of the enabling task; to be able to influence interaction between the employees.

The other three Democracy, Social milieu and Integration into the organization are factors directly concerned with the interaction between the employees. The significant increases in them suggests that the training in the enabling task has been successful, since one core of the task is to provide conditions for interaction between employees.

\subsection{Has the Training Changed the Interaction between Employees at the Workplace?}

We base our understanding of interaction on three theories: Balanced communication, dialogue, and improvisational approach. Changes in the perspective of the theory about improvisational approach are hard to measure with a questionnaire. This theory has been important for forming the interaction in the training, but we have not found any way to measures the effects of this.

The theory about Balanced communication focuses on a balance between inquiry-advocacy, other-self and positive-negative. Especially important is the ratio between positive and negative statements, which should be high to get high performance. The scale democracy from the Interaction-questionnaire showed that the training resulted in a more positive social climate; where all are involved, listened to and understood. This result is strengthened by the positive result in the social milieu scale of the questionnaire measuring employees' general experience of the work.

Theories about dialogue emphasize the ability to both talk, and listen and critical reflect. The scales interest and individual activity indicates that the training resulted in increased dialogue competence. Individual subordinates do talk actively more often; start a discussion to scrutinize what is said or give a deviant opinion and get enough time to develop their thoughts on the subject. And at the same time it is now more common to actively listen and reflect critically, ask if you do not understand and challenge and even change opinions.

Our conclusion is that the training in the director task has changed the interaction between employees at the workplace in a positive way. 


\subsection{Is There More of Integrated Autonomy at the Workplace?}

The factor analysis of the integrated autonomy questionnaire developed this theory further. We now realize the need to distinguish between different levels when it comes to integration and autonomy. The individual can be integrated into the group and/or into the organization. And autonomy can be exercised by an individual and/or a group.

Since there is an increase in all four of the scales based on these factors we conclude that there is more of integrated autonomy at the workplaces. But the theory also stresses the need for a balance between autonomy and integration (Backström, 2009). The results show a higher increase in the scales measuring the two aspects of integration, than those measuring autonomy. If the workplaces were already better in integration than in autonomy, this could be a negative result. We have to make further analyzes on a workplace level to be able to come to a firm conclusion about the result of integrated autonomy. We may have to develop the series of workshops so managers are better trained in giving autonomy to their co-workers.

\subsection{Weaknesses in the Results}

As always in this kinds of study it is hard to know if it is our implementation, the training of managers in the enabling task, that causes the positive results. We have a couple of arguments that this is so. Firstly, the project time coincided with the financial crisis and several of the included organizations suffered from the hard times. Thus, the general development of different aspects in most of the included organizations during the time of the project was negative. Secondly, we have made further analyses on work place level and been able to sort the different workplaces into five categories: Dramatic change in the face of recession, Major change and actively using this training intervention, Moderate change and difficulties using the intervention, Minor change and indifference, and Negative change with subsequent the loss of spirit (Wilhelmson et al., Forthcoming). There are several different reasons why some organizations had a less successful result. This variance shows a good correlation between how much the managers were able to use the training and the results of the training. We can say with confidence that for managers that had the possibility of using the training in their management work the result was a success.

\section{Acknowledgements}

Acknowledgements to Vinnova, the funder of the research project, and to all the managers and employees at the workplaces who so generously took part in the research work.

\section{References}

Argyris, W. R., \& Schön, D. (1978). Organisational learning: A theory of action perspective. Reading, Massachusets: Addison-Wesley. http://dx.doi.org/10.2307/40183951

Backström, T. (2009). How to organize for local resource generation. The Learning Organization, 16(3), 223-236. http://dx.doi.org/10.1108/09696470910949944

Backström, T., \& Döös, M. (2008). Relatonics - a key concept for networked organizations. In G. D. Putnik \& M. M. Cunha (Eds.), Encyclopedia of networked and virtual organizations (Vol. 3, pp. 1367-1374). Hershey, PA: Idea Group Inc. http://dx.doi.org/10.4018/978-1-59904-885-7.ch179

Backström, T., Döös, M., \& Wilhelmson, L. (2006). Chefen som regissör-ledarskap och medarbetarskapets självorganiserande processer [The directing manager-leadership and the self-organizing processes of co-workership]. In C. v. Otter (Ed.), Ledarskap för fria medarbetare-En antologi [Leadership for free employees-An anthology] (pp. 123-158). Stockholm, Swedish: National Institute for working life.

Backström, T., Hagström, T., \& Göransson, S. (2013). Communication as a mechanism for cultural integration. Nonlinear Dynamics, Psycholgy, and Life Sciences, 17(1).

Backström, T., Wilhelmson, L., Olsson, B. K., Åteg, M., \& Åberg, M. M. (2011). The Role of Manager in the Post-Industrial Work System. In E. Seglod, E. Berglund, E. Bjurström, E. Dahlquist, L. Hallén \& E. Johansson (Eds.), Studies in industrial renewal (pp. 215-227). Västerås: Mälardalen University Press.

Bales, R. F. (1950). Interaction process analysis: a method for the study of small groups. Cambridge: Addison-Wesley.

Barker, J. R. (1999). The discipline of teamwork-Participation and concertive control. Thousand Oaks, California: SAGE.

Bass, B. M. (1999). Two decades of research and development in transformational leadership. European Journal of Work and Organizational Psychology, 8, 9-32. http://dx.doi.org/10.1080/135943299398410 
Berger, P. L., \& Luckmann, T. (1966). The social construction of reality. A treatise in the sociology of knowledge. New York, USA: Doubleday \& Company.

Coates, J. (1996). Women talk. Conversation between women friends. Oxford: Blackwell Publishers Ltd.

Coates, J. (1997). One-at-a-time: The organization of men's talk. In H. Meinhof \& S. Johnson (Eds.), Language and masculinity. Cambridge Mass: Blackwell Publishers Inc.

Csikszentmihalyi, M. (1990). Flow: the psychology of optimal experience. New York: Harper \& Row.

Edquist, C., \& Johnson, B. (1997). Institutions and organizations in systems of innovation. In C. Edquist (Ed.), Systems of Innovation. Technologies, institutions and organizations. London: Pinter.

Flamholtz, E. G. (1986). How to make the transition from entrepreneurship to a professional managed firm. San Fransisco: Jossey-Bass.

Fleichman, E. A., \& Harris, E. E. (1962). Patterns of leadership behavior related to employee grievances and turnover. Personnel Psychology, 15, 43-55. http://dx.doi.org/10.1111/j.1744-6570.1962.tb01845.x

Follett, M. P. (1918). The new state: Group organization, the solution of popular government. New York: Longman, Greeen \& Co.

Hagström, T., Backström, T., \& Göransson, S. (2009). Sustainable competence: Reproduction and innovation in a bank. The Learning Organization, 16(3), 237-250. http://dx.doi.org/10.1108/09696470910949953

Haken, H. (1996). Principles of brain functioning. A synergetic approach to brain activity, behavior and cognition. Berlin: Springer.

Isaacs, W. (1999). Dialogue and the art of thinking together. New York: Currency Cop.

Janis, I. L. (1972). Victims of Groupthink. Boston: Houghton Mifflin Company.

Kurtzberg, T. R., \& Amabile, T. M. (2001). From Guilford to Creative Synergy: Opening the Black Box of Team-Level Creativity. Creativity Research Journal, 13(2), 285-294. http://dx.doi.org/10.1207/S15326934CRJ1334_06

Lewis, M. W. (2000). Exploring paradox: Toward a more comprehensive guide. Academy of Management Review, 25(4), 760-776. http://dx.doi.org/10.2307/259204

Losada, M. (1999). The Complex Dynamics of High Performance Teams. Mathematical and Computer Modeling, 30(9-10), 179-192. http://dx.doi.org/10.1016/S0895-7177(99)00189-2

Losada, M., \& Heaphy, E. (2004). The role of positivity and connectivity in the performance of business teams. American Behavioral Scientist, 47(6), 740-765. http://dx.doi.org/10.1177/0002764203260208

Olsson, B. (2007). Languages for creative interaction: descriptive language in heterogeneous Groups. Paper presented at the The 10th European conference on creativity and innovation, ECCI-X, Copenhagen.

Olsson, B. (2008). In Swedish, Beskrivningsspråk i och för kreativ praxis: Idéutveckling under gruppsession [Descriptive languages in and for creative practice: Idea development during group sessions]. Doctoral Dissertation 1651-4238; 68. [In Swedish] Mälardalen University Press: Västerås, Sweden.

Sánchez-Runde, C. J., \& Pettigrew, A. M. (2003). Managing dualities. In Pettigrew et al. (Eds.), Innovative forms of organizing. London: SAGE. http://dx.doi.org/10.4135/9781446219386.n10

Sawyer, R. K. (2001). Creating Conversations: Improvisation in Everyday Discourse. New Jersey: Hampton Press.

Shweder, R. A., \& Sullivan, M. A. (1993). Cultural psychology: Who needs it? Annual Reviews Psychology, 44, 497-523. http://dx.doi.org/10.1146/annurev.psych.44.1.497

Streatfield, P. J. (2001). The paradox of control in organizations. London: Routledge.

Surie, G., \& Hazy, J. K. (2006). Generative leadership: Nurturing innovation in complex systems. Emergence: Complexity \& Organization, 8(4), 13-26.

Wilhelmson, L. (1998). Lärande dialog. Samtalsmönster, perspektivförändring och lärande i gruppsamtal [Learning dialogue. Conversation patterns, perspectives change and learning in a group conversations]. [In Swedish]. Stockholm: Arbetslivsinstitutet. Document Number

Wilhelmson, L. (2002). On the theory of transformative learning. In A. Bron \& M. Schemmann (Eds.), Social science theories in adult education research (pp. 180-210). Münster: LIT verlag. 
Wilhelmson, L. (2006). Dialogue meetings as nonformal adult education in a municipal context. Journal of Transformative Education, 4(3), 243-256. http://dx.doi.org/10.1177/1541344606290439

Wilhelmson, L., Åberg, M. M., Backström, T., Olsson, B. K., \& Åteg, M. (2013). Transformative learning in the workplace-a research intervention (in pressing).

Yukl, G. (2002). Leadership in organizations. Eaglewood Cliffs: Prentice-Hall.

\section{Copyrights}

Copyright for this article is retained by the author(s), with first publication rights granted to the journal.

This is an open-access article distributed under the terms and conditions of the Creative Commons Attribution license (http://creativecommons.org/licenses/by/3.0/). 